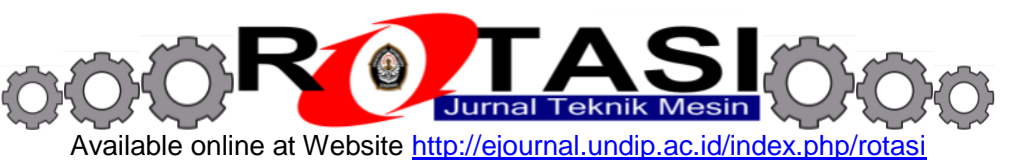

\title{
DESAIN DAN ANALISIS TEGANGAN PADA SISTEM PERPIPAAN LEPAS PANTAI UNTUK SPM 250,000 DWT
}

\author{
*Toni Prahasto ${ }^{a}$, Djoeli Satrijo ${ }^{a}$, I Nyoman Chandra Kusuma ${ }^{b}$ \\ a'Dosen Departemen Teknik Mesin, Fakultas Teknik, Universitas Diponegoro \\ ${ }^{b}$ Mahasiswa Departemen Teknik Mesin, Fakultas Teknik, Universitas Diponegoro \\ Jl. Prof. Sudharto, SH., Tembalang-Semarang 50275, Telp. +62247460059 \\ *E-mail: inyomanck@yahoo.co.id
}

\begin{abstract}
ABSTRAK
Perancangan sistem perpipaan bawah laut ini mengacu pada code ASME B31.4 chapter IX. Sistem perpipaan ini terdiri dari sistem perpipaan onshore dan offshore dan terdiri dari 2 buah pipa dengan jenis pipa twin pipe dengan dimensi yang sama. Jalur pipa ini offshore ini memiliki jalur dari SPM 250,000 DWT menuju tangki storage yang berada di daratan balongan. Jalur pipa ini memiliki tekanan operasi sebesar $1,070 \mathrm{KPa}$, temperatur operasi sebesar $70^{\circ} \mathrm{C}$ dan laju aliran fluida sebesar $1.85 \mathrm{~m}^{3} / \mathrm{s}$. Jalur perpipaan ini terletak di lepas pantai banyuwangi dengan karakteristik tanah yang didominasi oleh pasir dan diselingi lumpur. Kedua jalur perpipaan tersebut dimodelkan dengan gambar isometri menggunakan software PDMS dan dianalisa tegangannya menggunakan software Caesar II. Hasil analisa tegangan pada Caesar II menjukkan bahwa nilai tegangan tertinggi terdapat pada bagian tee di bagian pipa bawah laut dengan nilai sebesar $369,344.564 \mathrm{KPa}$ dan intensitas tegangan tertingginya 379,615.68 KPa dengan tegangan ijinnya 403,343.3 KPa. Ini terjadi pada pembebanan operation akibat berat, tekanan, temperatur pipa dan gelombang/arus. Rasio perbandingan frekuensi vortex dan frekuensi natural pada sistem perpipaan pada masing-masing jalur memiliki perbedaan yang signifikan sehingga sistem perpipaan ini dapat terhindar dari resonansi. Tekanan kritis (Ppr) untuk kedua jalur tersebut adalah 11,318.521 KPa, sedangkan tekanan eksternalnya (Pe) sebesar 402.210 KPa. Nilai Pe < Ppr, sehingga sistem perpipaan ini terhindar dari fenomena buckling.
\end{abstract}

Kata kunci: ASME B31.4 chapter IX; buckling; frekuensi vortex; sistem perpipaan; tegangan.

\section{PENDAHULUAN}

Sistem perpipaan sangat diperlukan dalam industri minyak dan gas sebagai media untuk mendistribusikan fluida (zat cair dan gas) dari suatu tempat ke tempat lainnya. Untuk mengalirkan suatu fluida (cair atau gas) dari satu atau beberapa titik ke satu atau beberapa titik lainnya digunakan suatu media berupa pipa. Gabungan dari pipa-pipa yang memiliki panjang dan digunakan untuk mengalirkan fluida dari suatu peralatan ke peralatan lainnya yang beroperasi pada suatu plant disebut sistem perpipaan (piping system). Dalam sistem perpipaan terdapat komponen-komponen seperti katup, flange, elbow, percabangan, nozzle, reducer, support, isolasi, dan lain-lain [1]. Pada aplikasi di lapangan, umumnnya pipa seamless digunakan untuk kondisi tekanan dan temperatur tinggi. Proses produksi pada pipa seamless salah satunya melalui proses ekstrusi yang dilakukan dengan cara menekan billet panas pada dies (cetakan) yang membentuk pipa [2].

Berdasarkan kondisi desain tekanan dan temperature yang terjadi, banyak hal-hal yang perlu ditinjau dalam perencanaan dengan berbagai pertimbangan yang mengacu pada standar ASME dan API seperti pemilihan ketebalan pipa atau schedule, dan perhitungan jarak antara support [4]. Kemudian dalam perancangan juga melakukan analisis tegangan untuk mengevaluasi bagian-bagian pada sistem perpipaan tersebut apakah aman atau terjadi kegagalan. Apabila melebihi tegangan yang diijinkan maka perlu dilakukan revisi atau penyesuaian pada rancangan agar tidak terjadi kegagalan [5].

Dalam perancangan suatu sistem perpipaan diperlukan analisis yang disesuaikan dengan kebutuhan guna memprediksi kegagalan yang mungkin terjadi sehingga mampu dihindari dan diminimalkan. Perancangan sistem perpipaan bawah laut sangat tergantung pada kedalaman, kondisi gelombang dan arus air laut sendiri [6]. Pada saat kegiatan perancangan dan pemasangan pipa ini juga harus memperhatikan kondisi tegangan yang akan terjadi [3]. Jenis beban yang sering terjadi pada sistem perpipaan bawah laut adalah jenis beban dinamik akibat dari pengaruh arus dan gelombang laut yang bisa berubah-ubah setiap waktu. Setelah pipa ini dipasang dan diletakkan di dasar laut, akan mendapatkan risiko yang akan menimbulkan kerusakan akibat gelombang dan arus laut pada daerah tersebut. Perancangan pipa bawah laut juga harus memperhatikan faktor-faktor seperti beban yang harus ditanggung pipa, efek tekanan dan ekspansi panas di sekitar pipa, dan temperatur pipa. Maka, proses analisa tegangan juga akan melibatkan faktor-faktor di atas agar perancangan pipa sesuai standar yang telah ditetapkan dan mencegah terjadinya kegagalan [7].

Adapun tujuan yang ingin dicapai penulis dalam penelitian ini adalah untuk memodelkan sistem perpipaan bawah laut (offshore pipeline dengan menggunakan PDMS (Plant Design Management System) kemudian menganalisa nilai tegangan yang terjadi pada sistem perpipaan sesuai standar ASME B31.4 chapter IX akibat beban sustain, occasional (gelombang/arus), operation dan expansion. Menganalisa getaran yang terjadi pada sistem perpipaan denga 
menggunakan CAESAR II kemudian menganalisa tegangan akibat beban fatique pada pipa yang terhubung dengan hose dan menganalisa umur pakai sistem perpipaan bawah laut.

\section{PEMODELAN SISTEM PERPIPAAN \\ 2.1 DIAGRAM ALIR}

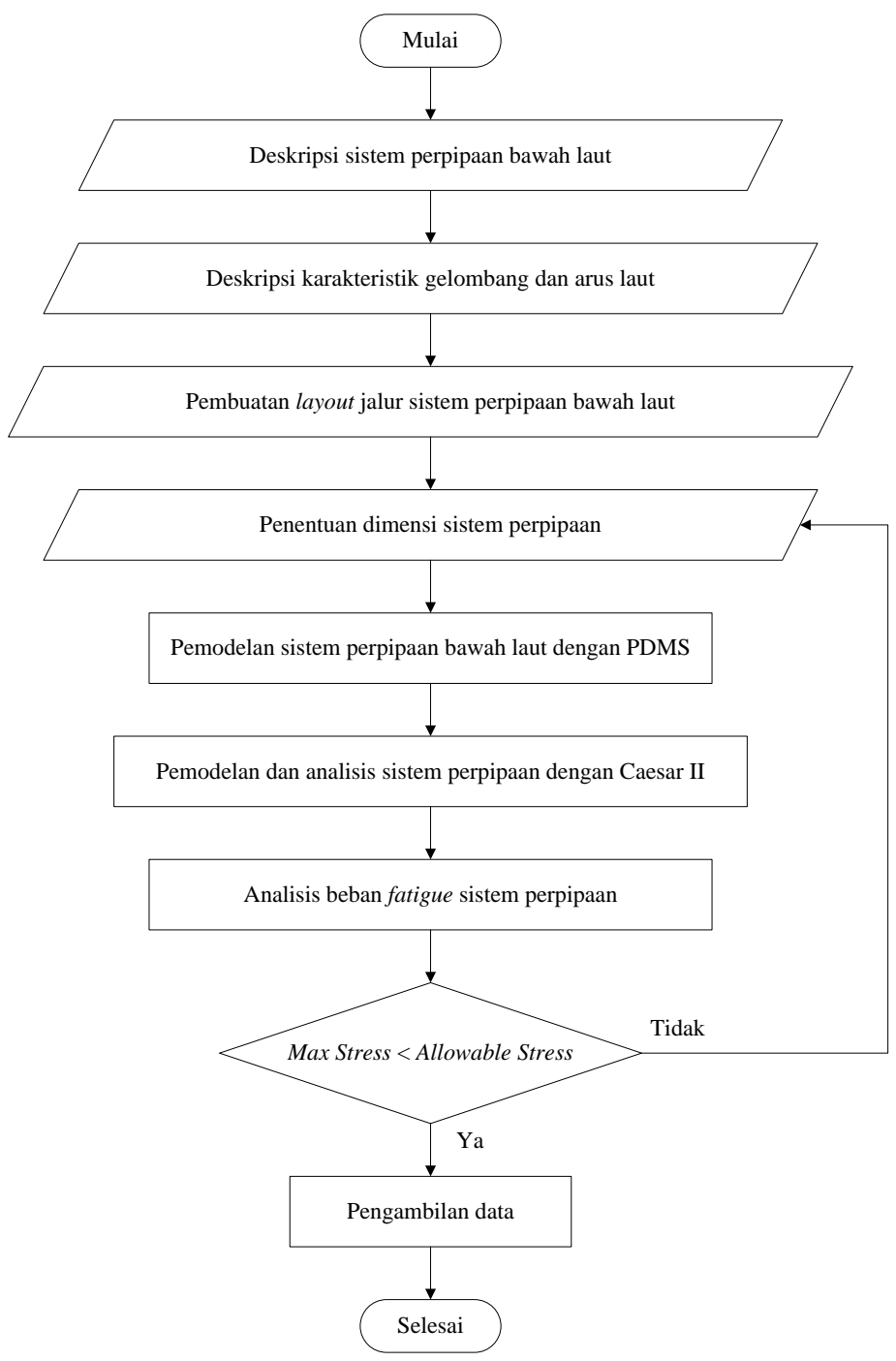

Gambar 1. Diagram Alir Penelitian

Tahapan awal untuk melakukan penelitian ini adalah mencari data lapangan yang akan dijadikan parameter masukan pada software Caesar II. Setelah data terkumpul, kemudian peneliti membuat desain keseluruhan menggunakan software Plant Design Management System (PDMS). Hasil isometrik dari PDMS tersebut kemudian dimodelkan dalam software Caesar II untuk dianalisa tegangan output dari sistem perpipaan ini [7].

\subsection{Pemodelan Plant Design Management System (PDMS)}

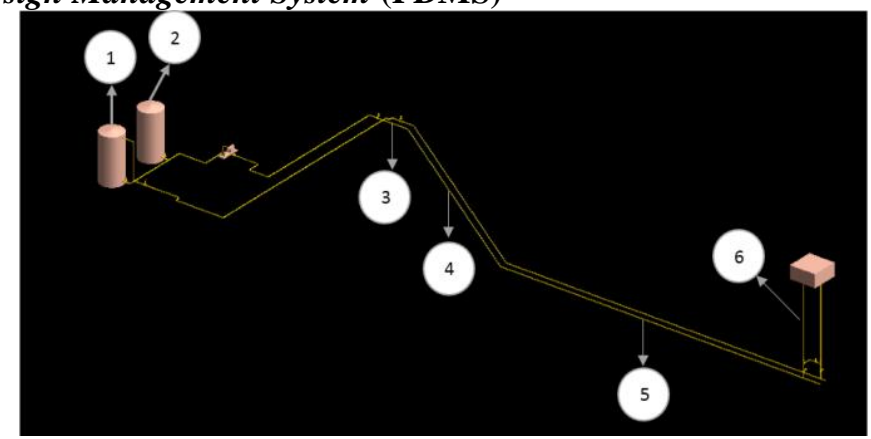

Gambar 2. Jalur sistem perpipaan dari onshore menuju offshore 


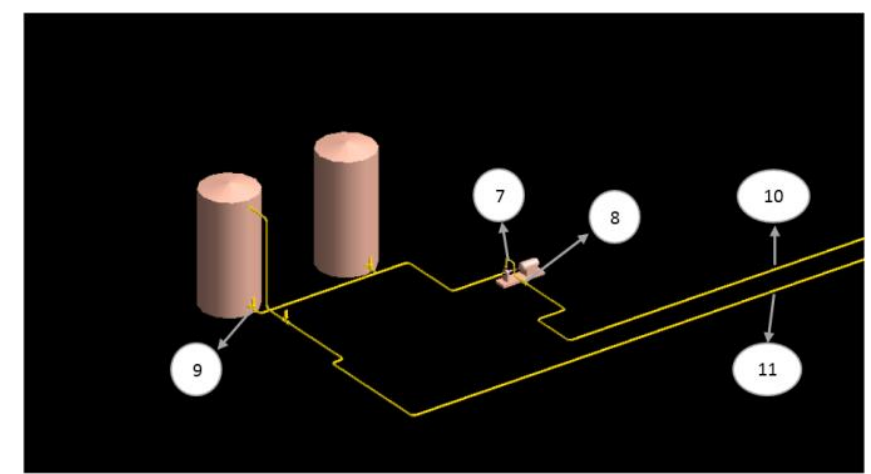

Gambar 3. Jalur sistem perpipaan, pompa dan valve

Keterangan:

1. Tangki Storage

2. Tangki Loading

3. Jalur Perbatasan Onshore-Offshore

4. Buried Pipeline

5. UnBuried Pipeline

6. Flexible Hose

7. Pompa

8. Check Valve

9. Gate Valve

10. Jalur Pipa Onshore To Offshore

11. Jalur Pipa Offshore To Onshore

Dalam proses simulasi di software Caesar II, sistem perpipaan akan diberikan berbagai variasi pembebanan yang meliputi:

a. Pembebanan sustain dimana memperhitungkan beban yang dihasilkan dari berat pipa dam tekanan internal dari pipa.
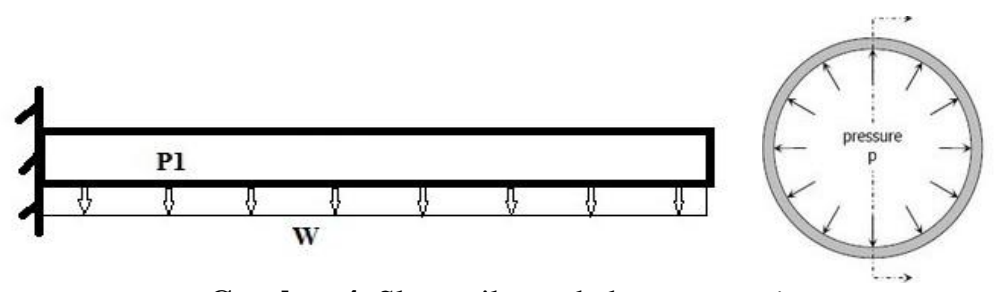

Gambar 4. Skematik pembebanan sustain

b. Pembebanan operation perlu diperhatikan karena pembebanan ini merupakan pembebanan sesungguhnya saat sistem perpipaan tersebut beroperasi. Kombinasi dari pembebanan ini karena berat, temperatur, tekanan internal, dan gelombang serta arus laut.
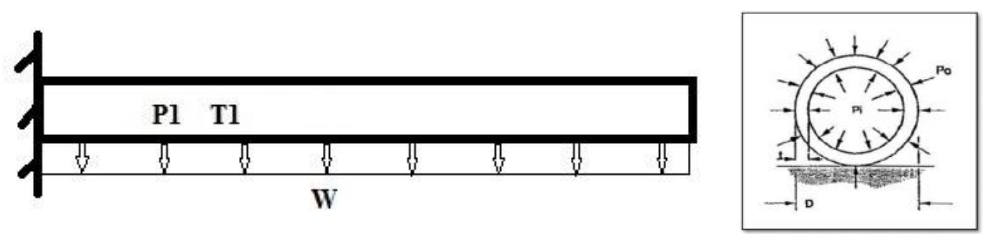

Gambar 5. Skematik pembebanan Operation

c. Pembebanan expansion dimana analisisnya memperhitungkan beban yang dihasilkan dari temperatur sehingga menimbulkan tegangan karena perpindahan dari bagian pipa.

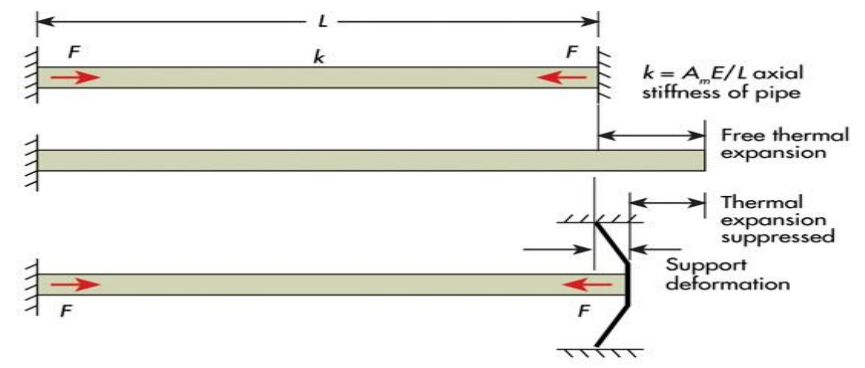

Gambar 6. Skematik pembebanan expansion 
d. Pembebanan occasional dimana analisisnya memperhitungkan beban yang dihasilkan dari berat pipa, tekanan internal dan gelombang serta arus laut [8].

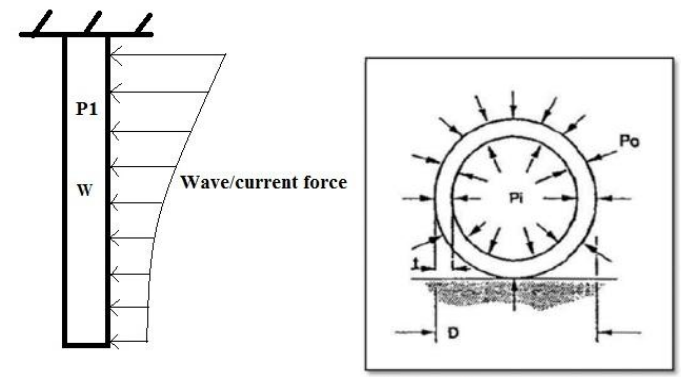

Gambar 7. Skematik pembebanan occasional

\subsection{FATIGUE LIFETIME SISTEM PERPIPAAN}

Software Caesar menampilkan tegangan tertinggi dan terendah yang terjadi pada sistem perpipaan ini. Hasilnya tegangan tertinggi berada pada pembebanan operasi karena adanya gelombang dan arus laut. Tegangan akibat gelombang ini akan menyebabkan fenomena fatigue pada sistem perpipaan. Oleh karena itu, dari tegangan tertinggi yang muncul dapat dihitung siklus kegagalan akibat fatigue pada sistem perpipaan ini. Perhitungan didasarkan pada kurva S-N menggunakan persamaan Goodman sebagai berikut [9]:

$\mathrm{S}_{\mathrm{u}}=$ ultimate stress of material

$\sigma_{\max }=1.5 \times 379.6 \mathrm{MPa}=569 \mathrm{MPa}$

$\mathrm{S}_{1000}=0.9 \times \mathrm{S}_{\mathrm{u}}$

Endurance limit

$\mathrm{S}_{\mathrm{e}}=0.5 \mathrm{~S}_{\mathrm{u}}$

Alternating Stress

$\sigma_{\mathrm{a}}=\frac{\sigma_{\max }-\sigma_{\min }}{2}$

Mean stress

$\sigma_{\mathrm{m}}=\frac{\sigma_{\max }+\sigma_{\min }}{2}$

Perhitungan tegangan siklik $\left(\mathrm{S}_{\mathrm{N}}\right)$ persamaan Goodman:

$\frac{\sigma_{\mathrm{a}}}{\mathrm{s}_{\mathrm{N}}}+\frac{\sigma_{\mathrm{m}}}{\mathrm{s}_{\mathrm{u}}}=1$

\section{HASIL DAN PEMBAHASAN}

Analisa sistem perpipaan dianalisa menggunakan standar ASME B31.4 chapter IX yang berfokus pada sistem perpipaan bawah laut. Sistem perpipaan bawah laut ini akan diberikan beban sustain, occasional, expansion dan operation. Hasil dari keempat pembebanan tersebut dijelaskan pada subbab di bawah ini:

\subsection{Pembebanan Sustain}

Pembebanan sustain pada jalur perpipaan bawah laut ini didapatkan nilai tegangan tertinggi sebesar 36,870.10 lb/sq.in $(254,210.4 \mathrm{KPa})$. Nilai tegangan ini masih dalam kondisi aman karena tidak melebihi tegangan yang diijinkan sebesar $58500 \mathrm{lb} . / \mathrm{sq}$.in $(403,343.3 \mathrm{KPa})$. Hasil perbandingan antara tegangan tertinggi dan tegangan yang diijinkan didapatkan rasio sebesar 63.02\%. Hasil intensitas tegangannya sebesar 37,114.80 lb./sq.in (255,897.53 KPa). 


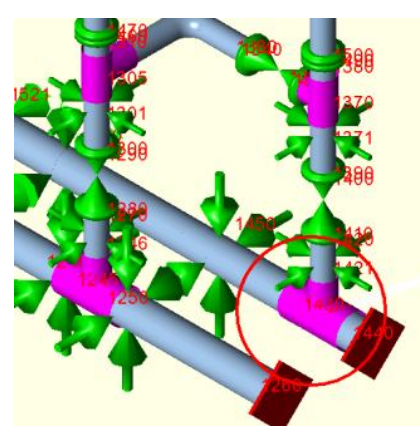

Gambar 8. Hasil Analisis Tegangan Sustain pada Jalur Perpipaan Bawah Laut dengan Caesar II

\subsection{Pembebanan Operation}

Pembebanan operation pada jalur perpipaan bawah laut ini didapatkan nilai tegangan tertinggi sebesar 53,568.90 lb/sq.in $(369,344.56 \mathrm{KPa})$ dan pembebenan operasi akibat pengaruh dari gelombang dan arus didapatkan nilai tegangan tertinggi sebesar 55,058.60 $\mathrm{lb} / \mathrm{sq}$.in $(379,615.68 \mathrm{KPa})$. Nilai tegangan ini masih dalam kondisi aman karena tidak melebihi tegangan yang diijinkan sebesar 58,500 lb./sq.in $(403,343,3 \mathrm{KPa})$. Hasil perbandingan antara tegangan tertinggi dan tegangan yang diijinkan didapatkan rasio sebesar 94.10\%. Hasil intensitas tegangannya sebesar 55,058.60 lb./sq.in $(379,615.68 \mathrm{KPa})$.

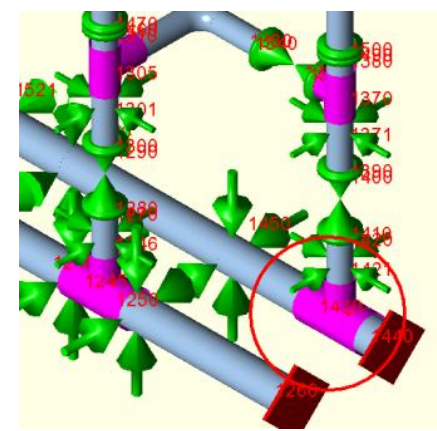

Gambar 9. Hasil Analisis Tegangan Operation Jalur Perpiaan dengan Caesar II

\subsection{Pembebanan expansion}

Pembebanan expansion pada jalur perpipaan bawah laut ini didapatkan nilai tegangan tertinggi sebesar 30,001.80 lb/sq.in $(206,855.12 \mathrm{KPa})$. Nilai tegangan ini masih dalam kondisi aman karena tidak melebihi tegangan yang diijinkan sebesar 58,500 lb./sq.in (403,343,30 KPa). Hasil perbandingan antara tegangan tertinggi dan tegangan yang diijinkan didapatkan rasio sebesar $51.28 \%$. Hasil intensitas tegangannya sebesar 30,008.20 lb/sq.in (206,899.25 KPa).

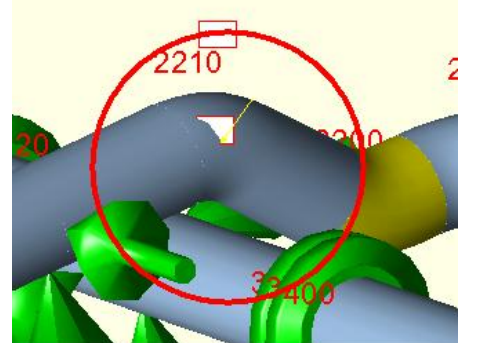

Gambar 10. Hasil Analisis Tegangan Expansion jalur Perpipaan dengan Caesar II

\subsection{Pembebanan Occasional}

Pembebanan occasional pada jalur perpipaan bawah laut ini didapatkan nilai tegangan tertinggi sebesar 45,139.80 lb/sq.in $(311,227.96 \mathrm{KPa})$. Nilai tegangan ini masih dalam kondisi aman karena tidak melebihi tegangan yang diijinkan sebesar 58,500 lb./sq.in (403,343,30 KPa). Hasil perbandingan antara tegangan tertinggi dan tegangan yang diijinkan didapatkan rasio sebesar 77.16\%. Hasil intensitas tegangannya sebesar 45,365.10 lb./sq.in (312,781.35 KPa). 


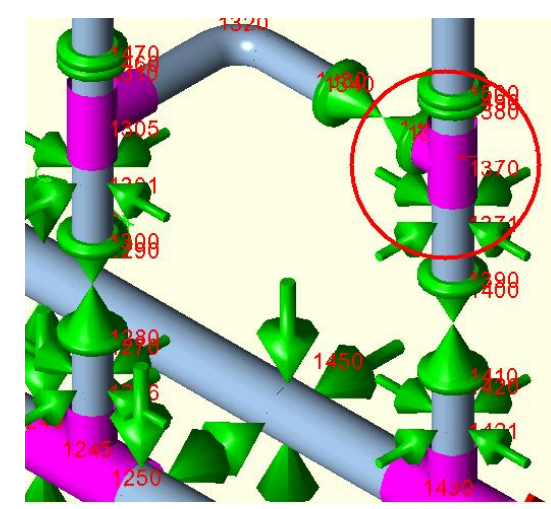

Gambar 11. Hasil Analisis Tegangan Occasional Jalur Perpipaan pada Caesar II

\subsection{Tegangan pada Sambungan Hose Dan Pipa}

Pada sistem perpipaan bawah laut ini terdapat Hose (selang) yang menghubungkan masing-masing jalur perpipaan menuju SPM. Hose ini mengalami eksitasi gaya akibat gelombang laut dan mengakibatkan beban fatique pada pipa yang terhubung langsung dengan hose. Beban fatique ini bisa perlu dipertimbangkan karena memungkinkan terjadinya kegagalan pada pipa. Berikut ini adalah tegangan yang muncul pada titik dimana pipa terhubung langsung dengan Hose tersebut.

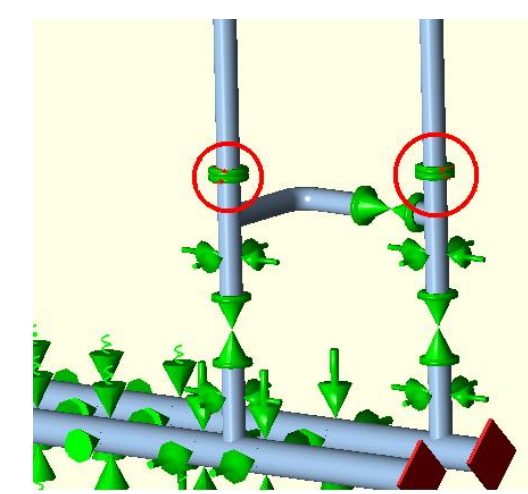

Gambar 12. Sambungan Hose Dan Pipa pada Jalur Perpipaan Bawah Laut

Tabel 1. Tegangan Akibat Beban Fatigue pada Jalur Perpipaan Bawah Laut

\begin{tabular}{lllll}
\hline Jalur & Node & $\begin{array}{l}\text { Tegangan } \\
(\mathbf{K P a})\end{array}$ & $\begin{array}{l}\text { Tegangan } \\
\text { ijin (KPa) }\end{array}$ & Rasio (\%) \\
\hline Onshore to offshore & 1460 & $40,186.80$ & & 12.50 \\
& 1470 & $56,497.02$ & & 17.50 \\
Offshore to onshore & 1490 & $40,186.80$ & $322,674,64$ & 12.50 \\
& 1500 & $56,497.02$ & & 17.50 \\
\hline
\end{tabular}

\subsection{Penentuan Lifetime Sistem Perpipaan}

Software Caesar menampilkan tegangan tertinggi dan terendah yang terjadi pada sistem perpipaan ini. Hasilnya tegangan tertinggi berada pada pembebanan operasi karena adanya gelombang dan arus laut [10]. Tegangan akibat gelombang ini akan menyebabkan fenomena fatigue pada sistem perpipaan. Tegangan ini perlu diperhatikan untuk mencegah terjadinya kegagalan yang dapat mempengaruhi struktur sistem perpipaan bawah laut ini akibat beban dari arus dan gelombang yang mengenai struktur perpipaan. Oleh karena itu, dari tegangan tertinggi yang muncul dapat dihitung siklus kegagalan akibat fatigue pada sistem perpipaan ini. Perhitungan didasarkan pada kurva S-N yang terlah dijelaskan pada bab sebelumnya. Dengan menggunakan persamaan Goodman maka akan didapatkan hasil perhitungan sebagai berikut:

Tabel 2. Perhitungan Endurance limit, Alternating Stress, dan Mean stress.

\begin{tabular}{ccccccc}
\hline No. & $\begin{array}{c}\boldsymbol{\sigma}_{\max } \\
(\mathbf{M P a})\end{array}$ & $\boldsymbol{\sigma}_{\min }(\mathbf{M P a})$ & $\begin{array}{c}\text { S1000 } \\
(\mathbf{M P a})\end{array}$ & $\begin{array}{c}\text { Endurance limit } \\
(\mathbf{M P a})\end{array}$ & $\begin{array}{c}\text { Alternating Stress } \\
(\mathbf{M P a})\end{array}$ & $\begin{array}{c}\text { Mean stress } \\
(\mathbf{M P a})\end{array}$ \\
\hline 1 & 569 & 0 & 581 & 323 & 284.5 & 284.5 \\
\hline
\end{tabular}


Perhitungan tegangan siklik persamaan Goodman:

Tabel 3. Perhitungan Tegangan Siklik

\begin{tabular}{cccc}
\hline No. & Alternating Stress $(\mathbf{M P a})$ & Mean stress $(\mathbf{M P a})$ & $\mathbf{S}_{\mathbf{N}}(\mathbf{M P a})$ \\
\hline 1 & 284.5 & 284.5 & 475 \\
\hline
\end{tabular}

Plot Menggunakan diagram Goodman:

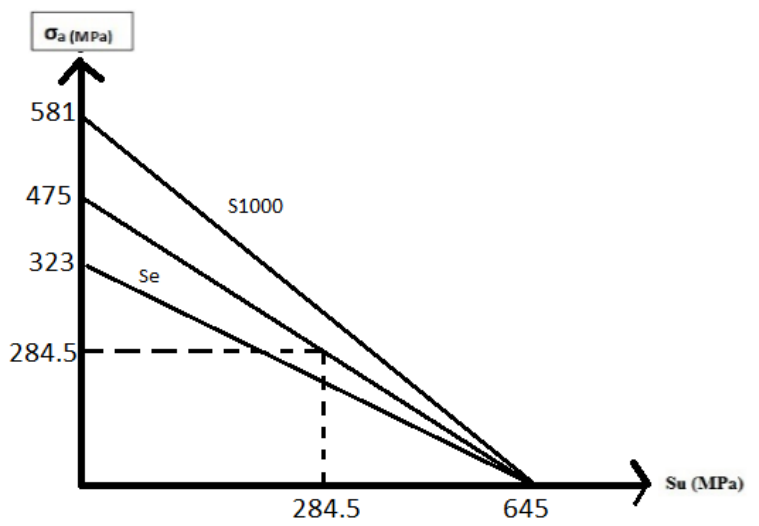

Gambar 13. Diagram Goodman

Jika diplot pada diagram S-N :

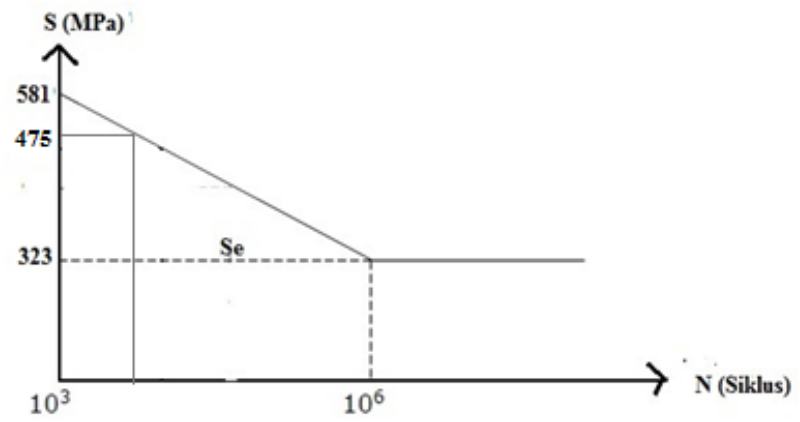

Gambar 14. Diagram S-N [5]

Dari hasil plot diagram S-N di atas didapatkan bahwa tegangan siklik yang terjadi di atas endurance limit sistem perpipaan dan jumlah siklusnya berada di antara $10^{3}-10^{6}$ siklus. Oleh karena itu untuk menentukan fatigue cycle secara spesifik digunakan persamaan S-N sebagai berikut:

Tabel 4. Perhitungan Persanaan S-N

\begin{tabular}{cccc}
\hline No. & $\mathbf{S}_{\mathbf{N}}(\mathbf{M P a})$ & $\mathbf{S}_{\mathbf{u}}(\mathbf{M P a})$ & $\mathbf{N}$ (Siklus) \\
\hline 1 & 475 & 645 & 10,667 \\
\hline
\end{tabular}

Dari hasil perhitungan didapatkan jumlah siklus sebesar 10,667 siklus sebelum terjadinya fatigue. Dalam prosesnya, waktu bongkar muat kapal tanker dilakukan seminggu satu kali dan waktu total pompa melakukan on/off sebesar 1-2 detik dengan frekuensi node pertama, yaitu 4.7 Hz. Oleh karena itu, lifetime dari sistem perpipaan ini, yaitu dapat dioperasikan selama 22 tahun.

\section{KESIMPULAN}

Hasil analisis menggunakan Caesar II didapat tegangan maksimum pada sistem perpipaan bawah laut pada ketiga jalur masih dalam kondisi aman karena besarnya tidak melebihi batas tegangan ijin. Hasil tegangan tertinggi terdapat pada Tee dengan besar 379,615.68 KPa dan intensitas tegangan tertingginya 379,615.68 KPa. Ini terjadi pada 
pembebanan operation akibat berat, tekanan, temperatur pipa dan gelombang/arus. Tegangan tertinggi akibat beban fatique pada pipa yang tersambung langsung dengan Hose terletak pada jalur perpipaan sebesar 56,497.02 KPa. Tegangan ini masih dalam kondisi aman karena besarnya masih di bawah tegangan ijin dengan rasio 17.5\%. Jumlah siklus yang mungkin terjadi sebelum terjadinya fatigue sebesar 10,667 siklus dan dengan waktu bongkar muat kapal tanker seminggu satu kali, maka didapatkan lifetime sistem perpipaan 22 tahun.

\section{DAFTAR PUSTAKA}

[1] Akbar, C.N., 2014, “Analisa Sistem Perpipaan Dari Gas Scrubber Menuju Condensate Flash Drum Di Onshore Receiving Facility PT. Pertamina Hulu Energi west Madura Offshore," Analisa Sistem Perpipaan Dari Gas Scrubber, 1:2-4.

[2] Armansyah, 2009, “Analisis Tegangan Pada Jalur Pipa Propylene Akibat Pembebanan Ekspansi,” Analisis Tegangan Pada Jalur Pipa Propylene, 1:1-5.

[3] Guo, B. et al., 2005, "Offshore Pipeline," Oxford - UK: Gulf Proffesional Publishing.

[4] Hakim, A.L., 2011, "Perancangan Pipa Bawah Laut."

[5] Harsokoesoemo, H.D., 2004. "Pengantar Perancangan Teknik," Bandung: ITB.

[6] Kannappan, S., 1986. Introduction to Pipe Stress Analysis, John Wiley \& Sons.

[7] Peng, L.C., and Peng, T. L., 2009, "Pipe Stress Engineering,” American Society of Mechanical Engineers, New York.

[8] Veritas, D.N., 2012, "DNV-OS-F101: Submarine Pipeline Systems," Det Norske Veritas, Oslo.

[9] Veritas, D.N., 1981, "Rules For Submarine Pipeline Systems 1981," Det Norske Veritas, Oslo.

[10] Onate, E., 2009, "Structural Analysis with the Finite Element Method Linear Static," Structural Analysis with the Finite Element Springer, Barcelona. 